\title{
Influence of Mine Tunnel Wall Humidity on Electromagnetic Waves Propagation
}

\author{
Lingfei Cheng, Lili Zhang, and Jie Li \\ School of Electrical Engineering and Automation, Henan Polytechnic University, Jiaozuo 454000, China \\ Correspondence should be addressed to Lingfei Cheng, bxd@hpu.edu.cn
}

Received 9 October 2011; Revised 26 December 2011; Accepted 26 December 2011

Academic Editor: Hon Tat Hui

Copyright () 2012 Lingfei Cheng et al. This is an open access article distributed under the Creative Commons Attribution License, which permits unrestricted use, distribution, and reproduction in any medium, provided the original work is properly cited.

High moisture in mine tunnel can cause the change of the permittivity and conductivity of tunnel walls, therefore influence the characteristics of electromagnetic waves propagation. This paper analyzes the mechanism of humidity influencing the permittivity and conductivity and attenuation of electromagnetic waves propagation in the circular tunnel and rectangular tunnel. The study result shows that, in the interest frequency range, the change of permittivity caused by humidity has little effect on propagation attenuation, but the effect on the conductivity change cannot be ignored. When the humidity is greater than a certain value, the attenuation will be increased significantly.

\section{Introduction}

In China, underground mining is the uppermost form of coal mining. There are a lot of factors having a significant impact on mobile communications in mine tunnels, such as limited spaces, the corner and branch of tunnels, roughness and tilt of tunnel wall, mine dust in tunnels, and obstacles [1]. Mine dust is harmful to workman health. The most common dedusting method is prewetting. Absorbing the moisture, the electrical parameters of tunnel walls will change, thus affect the propagation of electromagnetic waves.

In recent decades, there were many research works on electromagnetic waves propagation in tunnels. Emslie et al. [2] deduced the approximate solution of propagation attenuation in rectangular tunnel of nonideal conductive wall and gave the attenuation expression for the horizontal polarization and vertical polarization in lower transverse electric mode. Sun [3] studied the influence of electrical parameters of tunnel walls on the propagation and proposed the concept of conductivity breakpoint, where the influence of conductivity is minor and can be ignored when the conductivity value is low, and the influence is significant when the conductivity value is bigger than the certain value. Zhao [4] and Wei [5-7] studied the influence of moisture, aerosol droplets, and wet tunnel walls on the electromagnetic waves propagation.
This paper mainly studies the humidity of tunnel walls influencing the permittivity and conductivity and affecting the propagation of electromagnetic waves.

\section{Electromagnetic Waves Propagation Model in Tunnels}

2.1. Circular Tunnel Model. The attenuation constants of the circular waveguide in different modes are given by [8]

$$
\begin{gathered}
\alpha_{0 n} \approx 8.686 \frac{\chi_{1 n}^{2}}{k_{0}^{2} a^{3}} \begin{cases}\operatorname{Re}\left(\frac{1}{\sqrt{\varepsilon_{r}^{\prime}-1}}\right) & \mathrm{TE}_{0 n} \text { modes, } \\
\operatorname{Re}\left(\frac{\varepsilon_{r}^{\prime}}{\sqrt{\varepsilon_{r}^{\prime}-1}}\right) & \mathrm{TM}_{0 n} \text { modes, }\end{cases} \\
\alpha_{m n}^{ \pm} \approx 8.686 \frac{\chi_{m \pm 1, n}^{2}}{k_{0}^{2} a^{3}} \operatorname{Re}\left(\frac{\varepsilon_{r}^{\prime}+1}{2 \sqrt{\varepsilon_{r}^{\prime}-1}}\right) \quad \mathrm{EH}_{m n}^{ \pm} \text {modes, }
\end{gathered}
$$

where $\alpha$ is attenuation in $\mathrm{dB} / \mathrm{m}, m n$ is the order of modes, and $\chi_{1 n}$ is the $n$th nonvanishing root of the first-order Bessel function; $\varepsilon_{r}^{\prime}=k_{1}^{2} / k_{0}^{2}$ is the relative complex permittivity of the surrounding rock, where $k_{1}=\sqrt{\omega^{2} \mu_{1} \varepsilon_{1}^{\prime}}, k_{0}=\sqrt{\omega^{2} \mu_{0} \varepsilon_{0}}$, $\varepsilon_{1}^{\prime}=\varepsilon_{1}-j \sigma_{1} / \omega$ is the relatively complex permittivity, $\omega$ is the radian frequency, $\varepsilon_{1}, \mu_{1}$, and $\sigma_{1}$ are the permittivity, permeability, and conductivity of tunnel walls, respectively, 
and $\varepsilon_{0}$ and $\mu_{0}$ are the permittivity and permeability of the air; $a$ is the radius of the circular tunnel; $\operatorname{Re}(\cdot)$ is the real part of the complex variable.

2.2. Rectangular Tunnels Model. The attenuation constants of rectangular waveguide different modes are given by [2]

$$
\begin{aligned}
& \alpha_{E_{h}\left(n_{1}, n_{2}\right)}=4.343 \lambda^{2}\left(\frac{n_{1}^{2} \varepsilon_{1}}{a^{3} \sqrt{\varepsilon_{1}-1}}+\frac{n_{2}^{2}}{b^{3} \sqrt{\varepsilon_{2}-1}}\right), \\
& \alpha_{E_{v}\left(n_{1}, n_{2}\right)}=4.343 \lambda^{2}\left(\frac{n_{1}^{2}}{a^{3} \sqrt{\varepsilon_{1}-1}}+\frac{n_{2}^{2} \varepsilon_{2}}{b^{3} \sqrt{\varepsilon_{2}-1}}\right),
\end{aligned}
$$

where $\alpha$ is attenuation in $\mathrm{dB} / \mathrm{m}$, and $\left(n_{1}, n_{2}\right)$ is the order of $E_{h}\left(n_{1}, n_{2}\right)$ and $E_{v}\left(n_{1}, n_{2}\right), a$ and $b$ are the width and height of the rectangular tunnel, respectively, $\varepsilon_{1}$ is the relative permittivity of the two side wall, and $\varepsilon_{2}$ is the relative permittivity of tunnel top and bottom.

If the conductivity is considered, the relative permittivity in formula (2) is replaced by the relatively complex permittivity as follows

$$
\begin{aligned}
\alpha_{E_{h}\left(n_{1}, n_{2}\right)}= & 4.343 \lambda^{2} \operatorname{Re}\left[\frac{n_{1}^{2} \varepsilon_{r 1}^{\prime}}{a^{3} \sqrt{\varepsilon_{r 1}^{\prime}-1}}+\frac{n_{2}^{2}}{b^{3} \sqrt{\varepsilon_{r 2}^{\prime}-1}}\right]-4.343 \\
& \times \frac{\lambda^{3}}{2 \pi} \operatorname{Im}\left[\frac{n_{1}^{2} \varepsilon_{r 1}^{\prime 2}}{a^{4}\left(\varepsilon_{r 1}^{\prime}-1\right)}+\frac{n_{2}^{2}}{b^{4}\left(\varepsilon_{r 2}^{\prime}-1\right)}\right], \\
\alpha_{E_{v}\left(n_{1}, n_{2}\right)=} & 4.343 \lambda^{2} \operatorname{Re}\left[\frac{n_{1}^{2}}{a^{3} \sqrt{\varepsilon_{r 1}^{\prime}-1}}+\frac{n_{2}^{2} \varepsilon_{r 2}^{\prime}}{b^{3} \sqrt{\varepsilon_{r 2}^{\prime}-1}}\right]-4.343 \\
& \times \frac{\lambda^{3}}{2 \pi} \operatorname{Im}\left[\frac{n_{1}^{2}}{a^{4}\left(\varepsilon_{r 1}^{\prime}-1\right)}+\frac{n_{2}^{2} \varepsilon_{r 2}^{\prime 2}}{b^{4}\left(\varepsilon_{r 2}^{\prime}-1\right)}\right],
\end{aligned}
$$

where $\varepsilon_{r}^{\prime}=\varepsilon_{r}-j \sigma / \omega \varepsilon_{0}$.

\section{Influence of Humidity on Permittivity}

3.1. Permittivity and Humidity of Tunnel Wall. Rock permittivity is relative to water saturation, frequency, and lithology. Figure 1 showed the frequency dispersion characteristics of fine sandstone permittivity measured by Rock Physics Laboratory of China University of Petroleum from $1 \mathrm{kHz}$ to $3 \mathrm{GHz}$ [9], curve 1 for drying rock and curve 2 for $100 \%$ saturated rock.

As shown in Figure 1, when $f<100 \mathrm{MHz}$, the permittivity of saturated rock decreases with the frequency, while that of drying rock is almost the stable value of 4 . The value of saturated rock is significantly higher than the latter. When $f$ $>100 \mathrm{MHz}$, the permittivity of saturated rock is close to the stable value of 8 and the permittivity of drying rock to the value of 2.5 .

3.2. Influence of Permittivity on Electromagnetic Waves Propagation. According to formula (1), propagation attenuation curves of circular tunnels in saturated rock and drying rock are drawn in Figure 2, for tunnel radius is $2.5 \mathrm{~m}$, the conductivity of tunnel walls is $0.01 \mathrm{~S} / \mathrm{m}$, the permittivity of drying rock is 2.5 , and the permittivity of saturated rock is 8 .

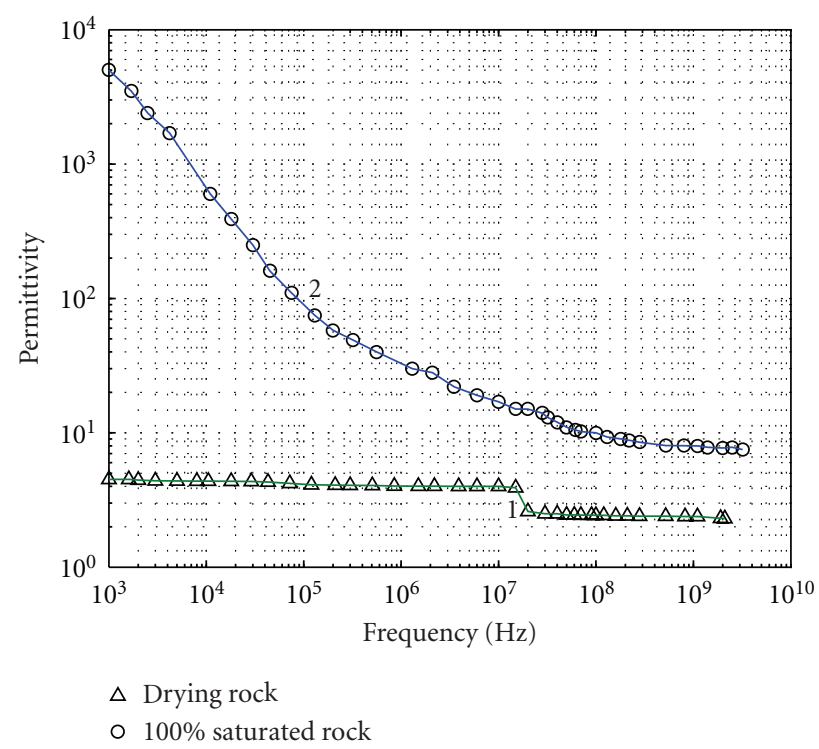

Figure 1: Frequency dispersion characteristics of fine sandstone permittivity from $1 \mathrm{kHz}$ to $3 \mathrm{GHz}$.

Obviously, propagation attenuation of saturated rock tunnel is higher than that of drying rock tunnel in $\mathrm{TM}_{01}$ mode and $\mathrm{EH}_{11}$ mode, but that is contrary in $\mathrm{TE}_{01}$ mode. However, the difference of propagation attenuation between both rock tunnels is small compared with the attenuation.

Similarly, propagation attenuation curves of rectangular tunnel of width $4 \mathrm{~m}$ and height $2.5 \mathrm{~m}$ are shown in Figure 3. It is seen that the difference between both rock tunnels is also small.

3.3. Summary. To sum up, the rock permittivity increases with the water saturation and decreases with the frequency, but tends to a stable value when $f>100 \mathrm{MHz}$. Whether in circular tunnels or rectangular tunnels, the difference of propagation attenuation between saturated rock tunnels and drying rock tunnels is small and negligible.

\section{Influence of Humidity on Conductivity}

4.1. Conductivity and Rock Moisture Content of Tunnel Wall. Generally, tunnel rock is composed of spherical particles and rock pores and the holes among particles fill with water. The rock moisture content $w$ and the conductivity of rock pore water $\sigma_{w}$ will impact on the wet rock conductivity $\sigma$ as follows [10]:

$$
\sigma=\sigma_{w} \cdot \frac{2 w}{3-w}
$$

where the range of $\sigma_{w}$ is from $0.1 \mathrm{~S} / \mathrm{m}$ to $1 \mathrm{~S} / \mathrm{m}$. Then, we can draw the curves of $\sigma$ changing with $w$ as shown in Figure 4.

It is seen that the rock conductivity increases with the rock moisture content, that is, humidity; moreover, the greater the conductivity of rock pore water is, the more apparent the increase trend of the rock conductivity is. 


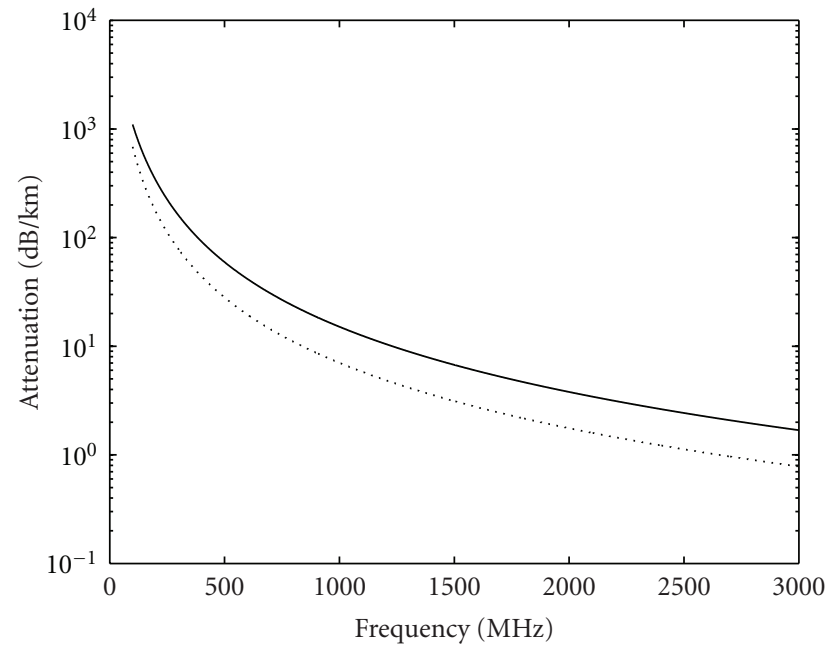

(a) $\mathrm{TE}_{01}$ mode

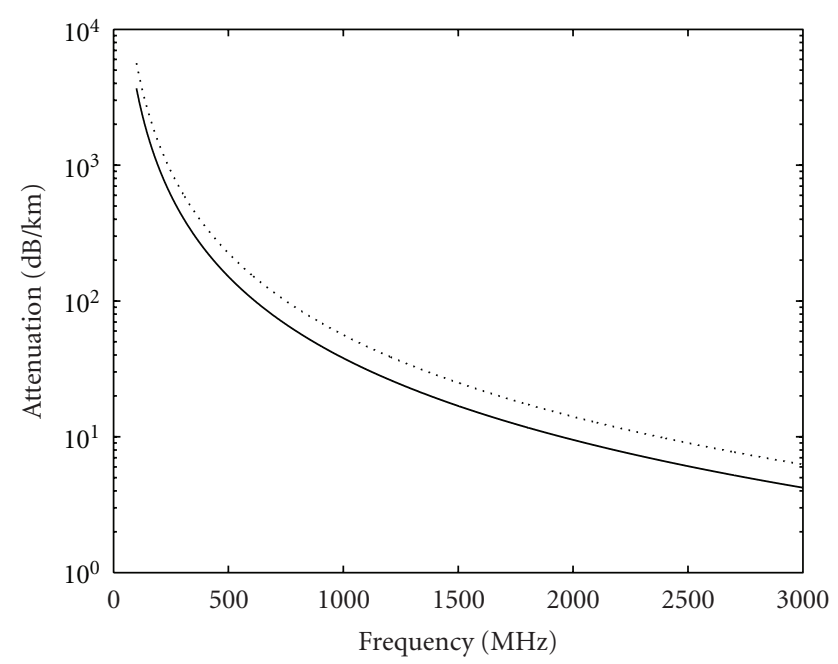

(b) $\mathrm{TM}_{01}$ mode

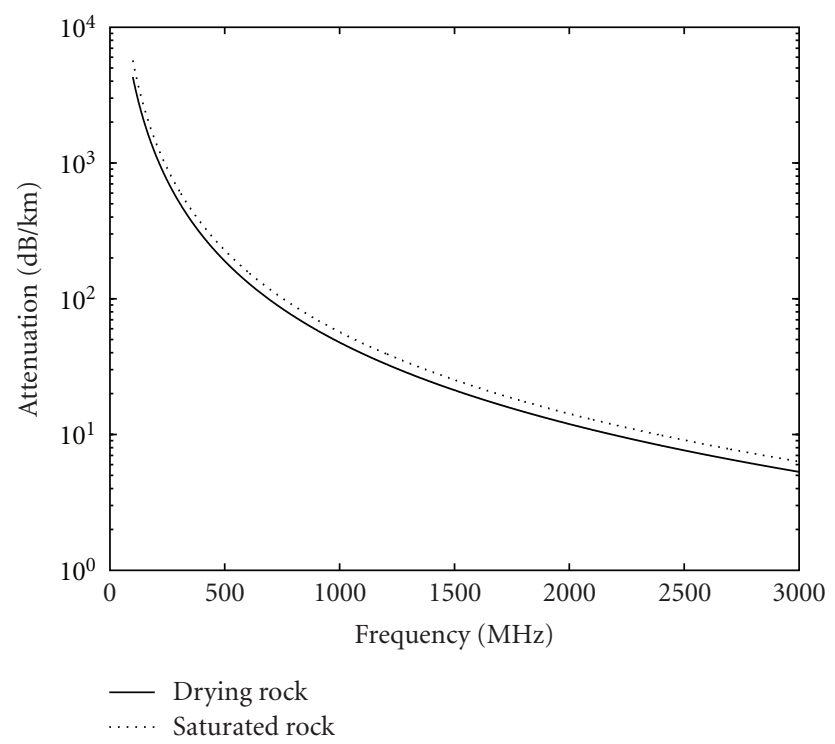

(c) $\mathrm{EH}_{11}$ mode

FIGURE 2: Propagation attenuation curves of circular tunnels in saturated rock and drying rock.

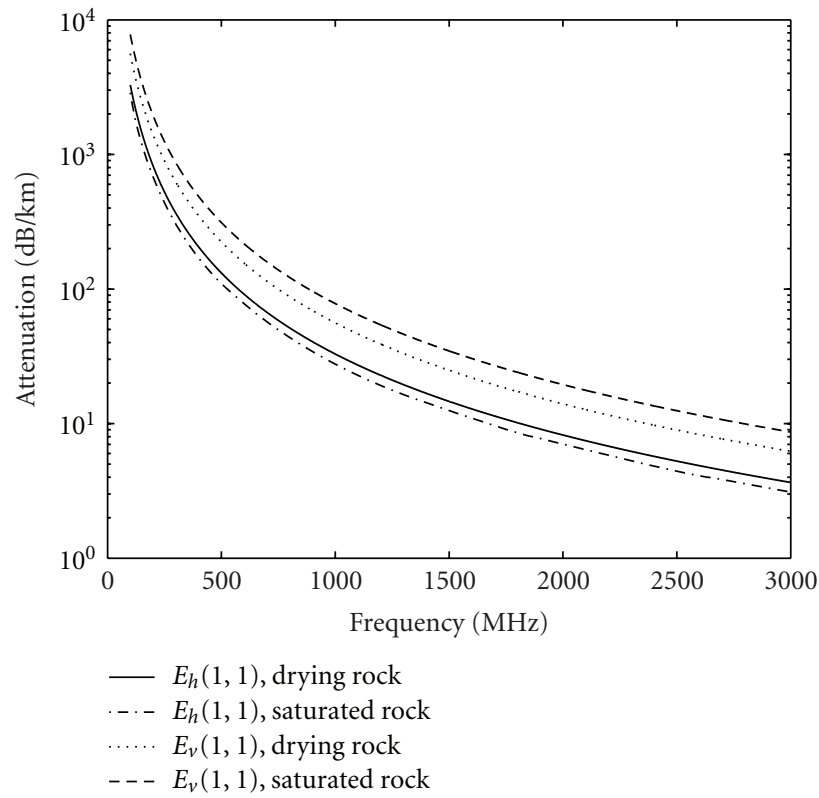

FIgURE 3: Propagation attenuation curves of rectangular tunnels in saturated rock and drying rock.

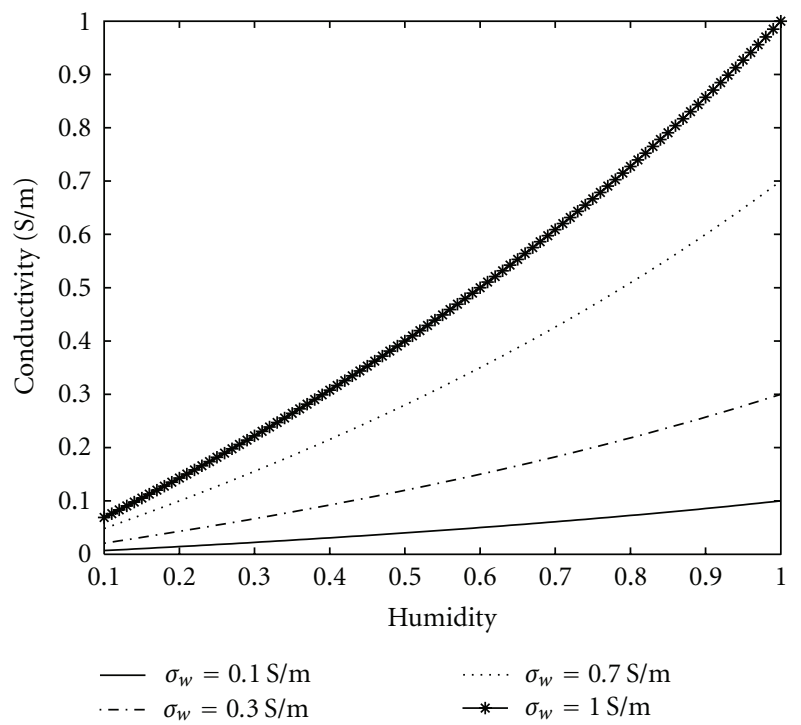

FigURE 4: Rock conductivity versus rock moisture content.

4.2. Influence of Humidity on Electromagnetic Waves Propagation. According to formulae (1) and (4), attenuation curves of circular tunnel in different modes are shown in Figure 5, for tunnel radius is $2.5 \mathrm{~m}$, the conductivity of rock pore water $\sigma_{w}=0.1 \mathrm{~S} / \mathrm{m}$, and $\sigma_{w}=1 \mathrm{~S} / \mathrm{m}$, respectively. In the same way, according to formulae (3) and (4), attenuation curves of rectangular tunnel of width $4 \mathrm{~m}$ and height $2.5 \mathrm{~m}$ are shown in Figure 6.

It can be seen in Figures 5 and 6 that, when the conductivity of rock pore water is $0.1 \mathrm{~S} / \mathrm{m}$, attenuation of different propagation modes has little change with the humidity of tunnel walls; when the conductivity of rock pore 


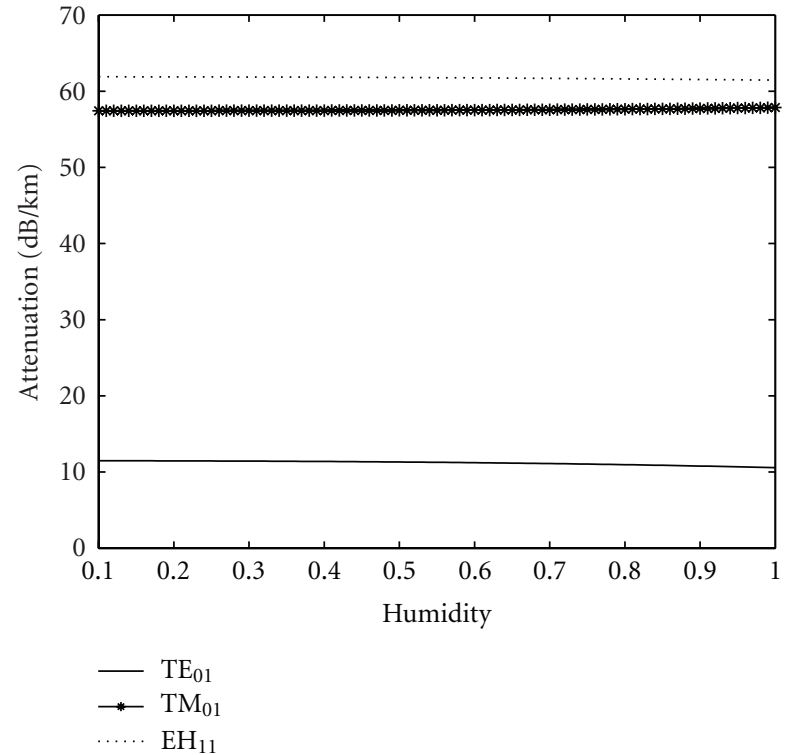

(a) $\sigma_{w}=0.1 \mathrm{~S} / \mathrm{m}$

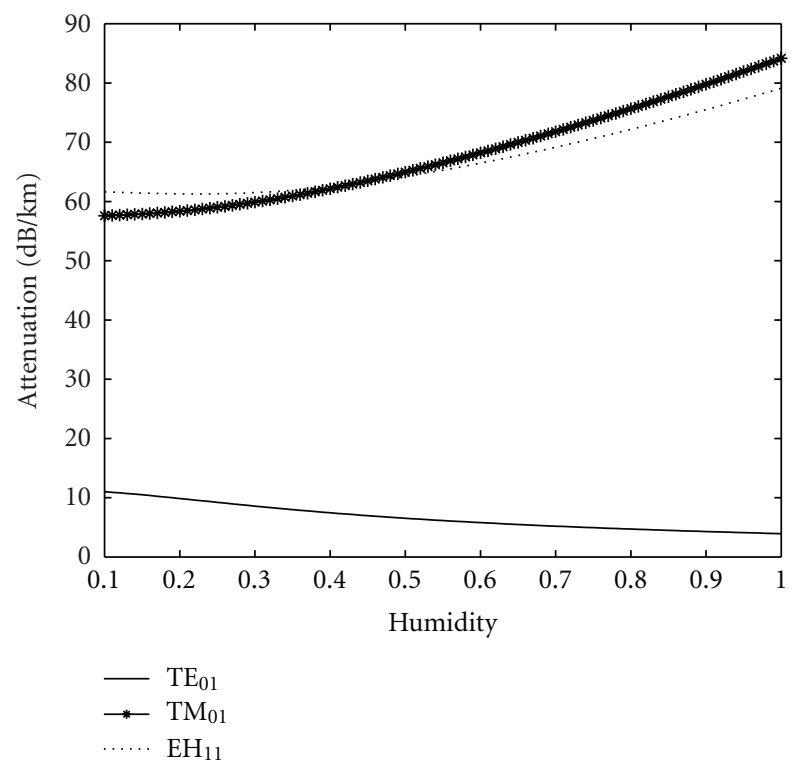

(b) $\sigma_{w}=1 \mathrm{~S} / \mathrm{m}$

FIGURE 5: Attenuation of circular tunnels versus humidity of tunnel walls.

water increases to $1 \mathrm{~S} / \mathrm{m}$, as the humidity value changes from 0.1 to 1 , attenuation of $\mathrm{TM}_{01}$ and $\mathrm{EH}_{11}$ mode in circular tunnels increases from about $60 \mathrm{~dB} / \mathrm{km}$ to $80 \mathrm{~dB} / \mathrm{km}$ and attenuation of $\mathrm{E}_{h}(1,1)$ mode in rectangular tunnels increases from $8 \mathrm{~dB} / \mathrm{km}$ to $13 \mathrm{~dB} / \mathrm{km}$.

4.3. Summary. As mentioned in [3], the effect of tunnel wall conductivity on electromagnetic wave attenuation is large or small, determined by the conductivity breakpoint.

When the pore water conductivity is low, the conductivity of tunnel walls cannot reach the conductivity breakpoint regardless of the humidity of tunnel walls. So, the effect

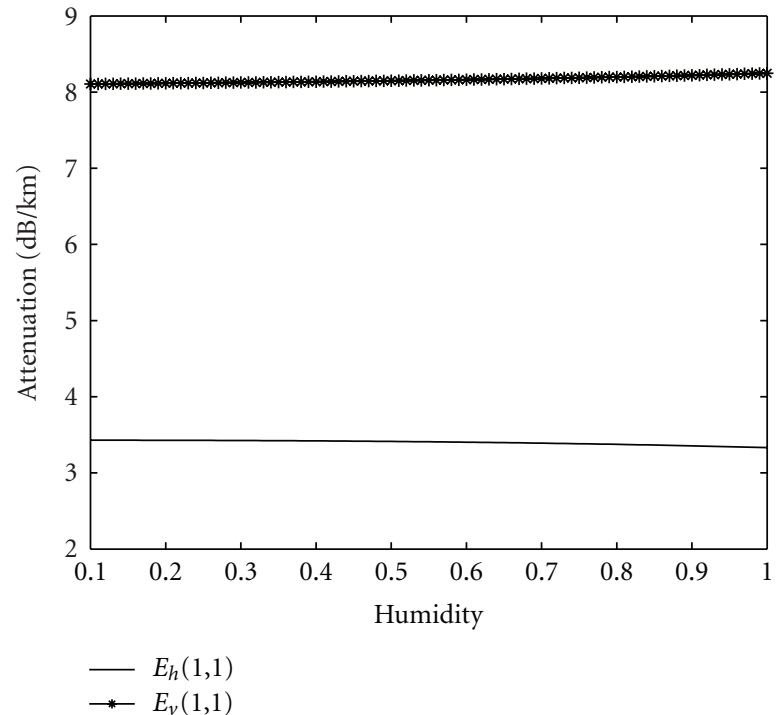

(a) $\sigma_{w}=0.1 \mathrm{~S} / \mathrm{m}$

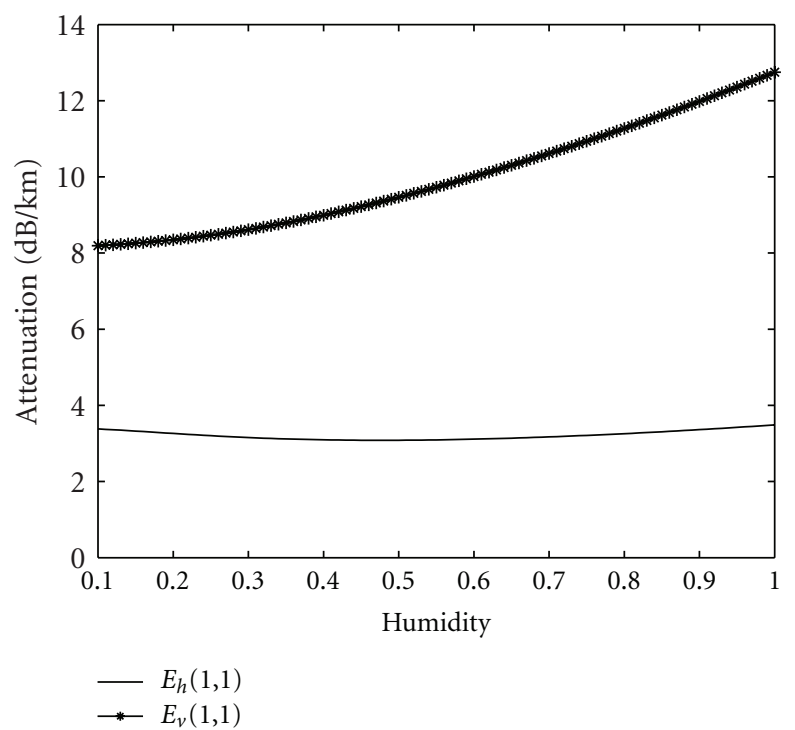

(b) $\sigma_{w}=1 \mathrm{~S} / \mathrm{m}$

Figure 6: Attenuation of rectangular tunnels versus humidity of tunnel walls.

of humidity on electromagnetic wave propagation is very small. When the pore water conductivity is great enough, the tunnel conductivity will increase markedly with humidity; once the conductivity is greater than the breakpoint, it will cause a great deal of attenuation of electromagnetic waves propagation.

\section{Conclusions}

Humidity of tunnel walls causes the change of the permittivity and conductivity, therefore influences the propagation of electromagnetic waves. In the circular tunnel of radius $2.5 \mathrm{~m}$ and rectangular tunnel of width $4 \mathrm{~m}$ and height $2.5 \mathrm{~m}$, at the frequency range of mine mobile communications, the 
effect of the permittivity on propagation caused by humidity is negligible, and the effect of the wall conductivity depends on the pore water conductivity. When the conductivity is low, the effect is small and negligible. However, when the conductivity is great enough, the humidity of tunnel walls will cause significant attenuation of electromagnetic waves propagation.

\section{Acknowledgments}

This paper was supported by Nature Science Foundation of He'nan Province (no. 102300410015), the Program for High School Technological Innovation Talents of He'nan Province (no. 2011HASTIT013), and Open Fund of He'nan Province Open Laboratory for Control Engineering Key Discipline (no. KG2009-17).

\section{References}

[1] J. Sun, "Technologies of monitoring and communication in the coal mine," Journal of China Coal Society, vol. 35, no. 11, pp. 1925-1929, 2010.

[2] A. G. Emslie, R. L. Lagace, and P. F. Strong, "Theory of the propagation of UHF radio waves in coal mine tunnels," IEEE Transactions on Antennas and Propagation, vol. 23, no. 2, pp. 192-205, 1975.

[3] J. Sun, L. Cheng, and X. Liu, "Influence of electrical parameters on UHF radio propagation in tunnels," in Proceedings of the Joint Conference of the 10th Asia-Pacific Conference on Communications and the 5th International Symposium on MultiDimensional Mobile Communications Proceedings (APCC/ MDMC '04), pp. 436-438, IEEE Press, September 2004.

[4] J. Zhao, "Discussion on influence factors of electro-magnetic wave's decay in roadway," Colliery Mechanical and Electrical Technology, no. 4, pp. 22-24, 2010.

[5] Z. Wei, J. Sun, and J. Lu, "Effects of cross sections of tunnel on propagation characteristics of electromagnetic waves," Journal of the University of Electronic Science and Technology of China, vol. 32, no. 6, pp. 620-623, 2003.

[6] Z. Wei, "Moisture in tunnel influenced to transmission features of electromagnetic wave," Coal Science and Technology, vol. 31, no. 2, pp. 39-41, 2003.

[7] H. Liu and Z. Wei, "Electromagnetic wave propagation attenuation change by wet tunnel wall," Journal of Xi an Uni- versity of Science \& Technology, vol. 25, no. 3, pp. 379-382, 2005.

[8] P. Delogne, Leaky Feeders and Subsurface Radio Communications, Peregrinus, London, UK, 1982.

[9] Well Logging Ology, Petroleum Industry Press, Beijing, China, 1998.

[10] S. Zhang and Y. Pan, Applied Geophysics Principle, China University of Geosciences Press, 2004. 

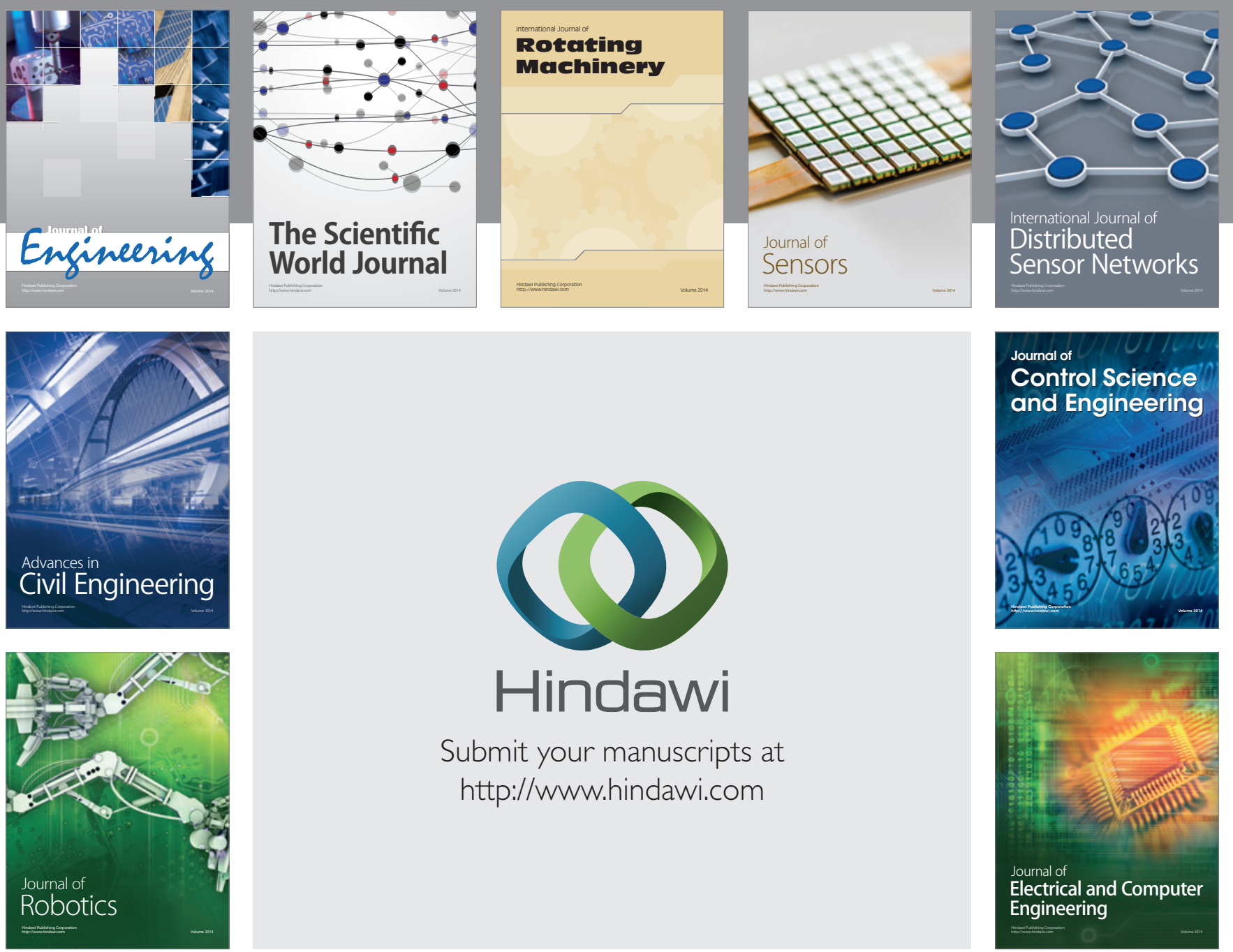

Submit your manuscripts at

http://www.hindawi.com
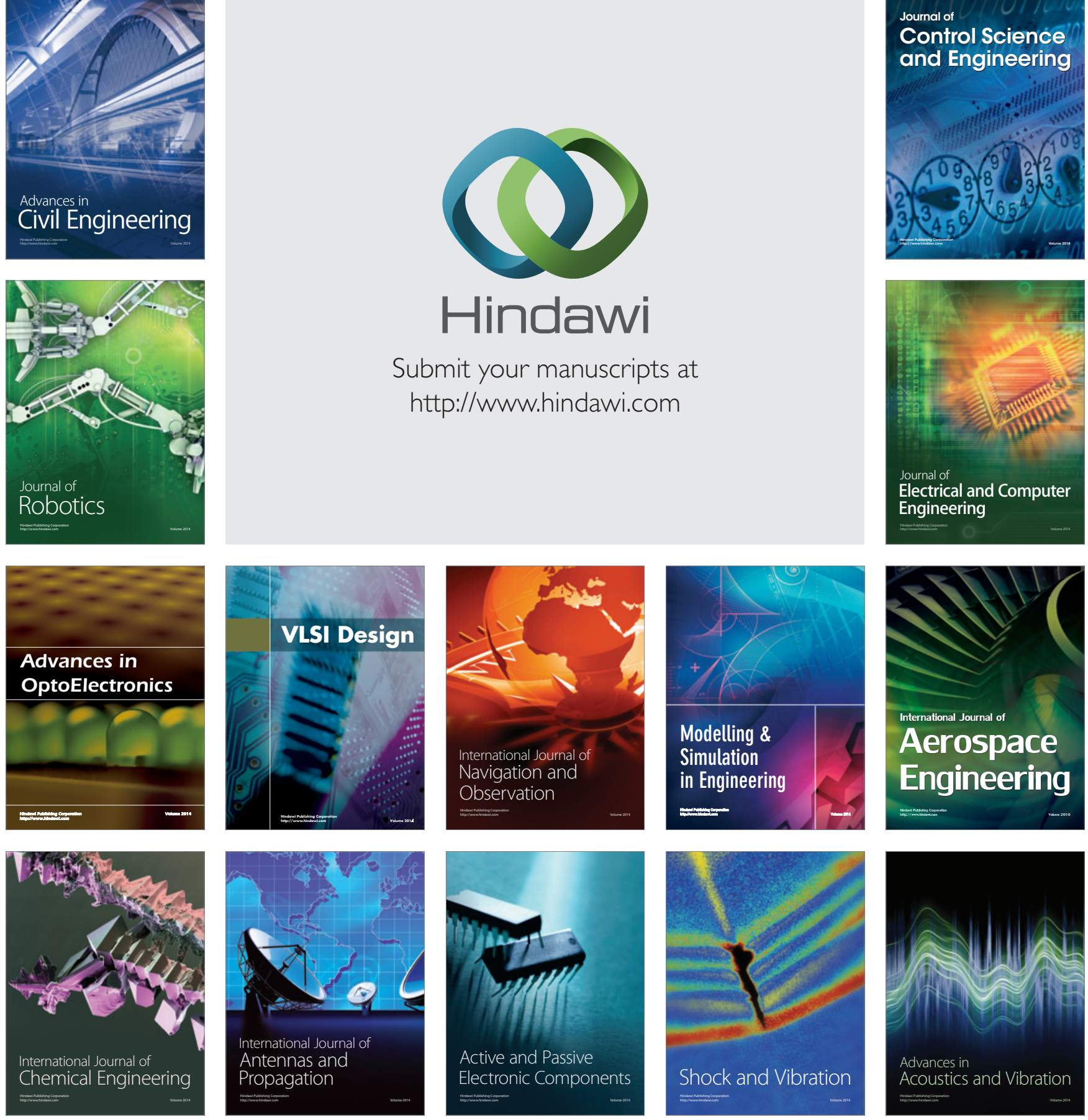